Revista Iberoamericana, Vol. LXIX, Núm. 202, Enero-Marzo 2003, 165-181

\title{
SALIDAS DE MADRE PARA SALIRSE DE MADRE
}

POR

Nora Domínguez

Universidad de Buenos Aires

A partir del juego de sentidos que se entabla entre madres y salidas, el título de este trabajo distingue en las primeras un lugar de comienzo. "Salirse de madre”, por su parte, apunta a una dirección que rechaza todo esencialismo y tiene a la sedición como propuesta. El pasaje forma parte de un programa de renovación simbólica que encuentra una de sus formas de expresión en un conjunto de ficciones que al discutir, alterar e interrogar los sitios naturalizados de la maternidad, los reinventa una y otra vez. Este ensayo procurará indagar ese espacio de solidaridad desviada que se tiende entre el sentido literal y descriptivo (el saberse salidas/nacidas de madre) que encierra la primera parte del título y el universo más metafórico (en tanto rebelión y salida de cauce) que implica la segunda. ${ }^{1}$

En 1969, Cristina Peri-Rossi publica Indicios pánicos, donde despliega ficciones de anticipación de hechos ocurridos durante las dictaduras de los años setenta que ponen en entredicho las relaciones entre vida y muerte, individuo y especie, sujeto e instituciones.

\footnotetext{
${ }^{1}$ El título, además, es la puesta en escena de una sustracción doble ejercida sobre dos antologías que reunieron textos de escritoras argentinas y chilenas agrupados según el eje temático de los vínculos afectivos entre madres e hijas. Me refiero a Salirse de madre, libro colectivo que reúne trece relatos y una obra de teatro de escritoras argentinas, y al volumen Salidas de madre. Las autoras argentinas varían entre aquéllas con mayor o menor producción literaria (Angélica Gorodischer, Alicia Steimberg, Mirta Botta) y otras que dan sus primeros pasos (Inés Hercovich). El libro incluye al final breves biografías, donde se leen distintas formas de la militancia feminista, lo que parece ser la base ideológica que estimuló la producción de un libro colectivo que revisara, a través de la ficción, las claves sociales y culturales de la maternidad. En general, las narradoras, colocadas en un lugar intermedio, interceden entre las representaciones de sus madres y de sus hijas, y juegan así con los puntos de contacto y diferenciación que se van dando en los relevos intergeneracionales. En cuanto a las apuestas literarias, se trata de textos heterogéneos, de disímil calidad narrativa. Creo que lo más destacable es el carácter colectivo de esta práctica de escritura feminista y el hecho de poner a circular y abrir, a través de la publicación, los sentidos diversos que puedan colocarse en la maternidad. El libro de las chilenas tiene una hechura completamente distinta. Se trata de una antología que reúne a diecinueve escritoras entre consagradas y noveles, realizada por pedido editorial, en momentos en que "somos mujeres quienes constituimos un $80 \%$ del mercado editorial". El conjunto incluye a escritoras con muy diferentes colocaciones en el campo intelectual, desde Isabel Allende y Marcela Serrano a Diamela Eltit y Pía Barros. La variedad de propuestas resulta un "compendio de historias de madres e hijas” y muestra las discrepancias en la percepción de la función materna.
} 
Otros textos escritos por mujeres en períodos posteriores recalan en el uso de figuraciones maternas para insistir en la reflexión sobre las relaciones entre familia, política y narrativa. La emergencia de los grupos de Madres y Abuelas de Plaza de Mayo en la escena política durante la dictadura argentina tiene una importancia crucial para el armado de nuevas prácticas y discursos maternos. Para desarrollar estas líneas de análisis me basaré principalmente en El cuarto mundo (1989) y “Consagradas” de Diamela Eltit y en El Dock (1993) de Matilde Sánchez. Finalmente incluiré algunas breves y puntuales referencias sobre textos publicados más recientemente como Ana M. 1945 (2001) de María Gabriela Ini, Divina anarquía (1998) de Belén Gache y Póstuma (2000) de la chilena Lina Meruane. El conjunto describe un arco amplio, narrativamente diverso y estéticamente variado de construcción ficcional de las relaciones madre-hijos.

EL FRASCO Y EL FISCO

Indicios pánicos, el libro de relatos de Cristina Peri-Rossi, contiene y combina apuestas narrativas diferentes, textos breves con relatos más extensos, poesía y prosa, dentro de un juego abierto y plural de codificaciones sobre el pánico social. En el prólogo escrito para la edición de 1980 Peri-Rossi señala:

En cierto momento de mi vida (tenía más de veinticinco años y menos de treinta) me pareció que yo tenía la aptitud para descubrir los indicios (que son siempre las señales materiales o inmateriales, los vestigios o las huellas de algo) del mundo que me rodeaba en mi país Uruguay. Es una cosa que a menudo le sucede a la gente joven, y yo lo era. Esta aptitud no dependía, supuse, del entorno circunstancial, aunque éste, por las especiales condiciones del momento fuera tan propicio. (Faltaban aún cinco años para el golpe militar, pero la atmósfera ciudadana estaba enrarecida, llena de presagios) (10)

La diseminación desbocada de estos detalles anticipan el horror de las dictaduras y se distribuyen en espacios interiores y exteriores, en casas y calles, afectan a hombres y mujeres, adultos y jóvenes, estudiantes, psicoanalistas o amas de casa. Bajo formas brutales pero imperceptibles acechan la cotidianidad, inquietando y borrando los límites entre lo humano y lo animal, la infancia y la vejez o tornando indecidibles los sexos y vistiendo de terror el borde que se tiende, enrarecido y violento, entre la vida y la muerte. En este contexto de significaciones amenazantes se destacan en este volumen algunos relatos que arman constelaciones de sentidos sobre la maternidad.

Madres e hijos en peligro actúan el pánico permaneciendo en estados antinaturales e invocan el estatismo y la detención en zonas que normalmente necesitan del movimiento, el tránsito y el proceso. El mundo exterior es tan terrible que una madre puede expulsar a su feto y conservarlo encerrado durante cuarenta y cinco años en un frasco. La mirada lúcida de la criatura y su evidente fuerza por haber sobrevivido a la voracidad de un gato y a la envidia de la madre le dan el empuje necesario para saltar e intercambiar el lugar con ella. Esta envejeció deseando el relevo; una y otro resuelven el espacio imaginario de la maternidad como un corredor estrecho a la medida de un tarro de vidrio, acuoso y siniestro, al mismo tiempo protector e intimidante. El relato 6 introduce a través de la primera 
persona de un bebé en el momento de su nacimiento el diálogo imaginario que durante el recorrido uterino mantienen el niño y su madre. Con magistral brevedad y eficacia narrativa el texto se pregunta por el adentro y el afuera, por el inevitable adentro que corresponde abandonar y el irresistible afuera que parece correcto descubrir. Otro de los relatos presenta a una niña que se instala rabiosamente en sus cinco años para poder imaginar siempre a una madre de veinticinco. Los tiempos se alteran, saltan las sucesiones generacionales, se detienen las progresiones. El pánico se piensa desde el título como un atributo generalizado que puede adherirse tanto a las imágenes siniestramente quietas de cuerpos sujetados y de desarrollo interrumpido como a aquéllas que los revelan víctimas de una fiebre de expansión. Si en uno de los textos la muerte es resistida con la inmovilidad del crecimiento, en otro son los desbordes del crecimiento los que provocan a la muerte. En el relato 29, una madre prepara con su sangre, su leche y gotas de semen una masa a la que machaca con fuerza; cerca del lugar de combate forma con premura al sobreviviente.

Los lugares que ocupan niños y madres en este libro de Peri-Rossi están marcados por un descentramiento, por una o varias dislocaciones. Embarazos, partos y nacimientos son narrados con maestría a través de una escena breve, desde perspectivas irrisorias, en mundos alucinados y alucinantes, con voces inadecuadas y violencias diversas y aglutinantes. Disponen así un espacio desquiciado donde se alteran los límites, posiciones, conductas y prácticas habituales de madres e hijos. Ese fuera del cuerpo materno que se ve en el niñomasa que se modela, en el feto que sobrevive en un frasco o en la madre que se sumerge en él actúan como la señal parlante de un estado de cosas que, inmersas en una poética fantástica, vaticinan el nivel de indefensión y vulnerabilidad de madres e hijos durante las dictaduras. Si bien las pistas anticipatorias que los relatos de Peri-Rossi despliegan son múltiples y variadas (guerras sordas y solapadas, detenciones callejeras, enfrentamientos urbanos, hombres-pájaro uniformados, documentos apilados durante años, funcionarios transformados en espías, persecución de jóvenes, profesores convertidos en mendigos, soldados armados en las calles, luchas, resistencias) las preocupaciones de los habitantes de estas ciudades por la vida y la muerte pero también por las políticas de natalidad y mortalidad y por el estilo de las sobrevivencias instalan el problema de la biopolítica como una cuestión central de estos gobiernos. Algunos de los relatos hacen de la procreación una finalidad absolutamente regulada por el Estado. Por ejemplo en "La desobediencia y la caída del oso” solo una entre veinte parejas está autorizada a procrear, en el relato 2 se hace mención a un nuevo impuesto que grava el derecho a la fecundidad. En este mismo relato se describe una ciudad de viejos que ante la falta de nacimientos y la huida de los jóvenes, se vuelven, además de una carga insoportable, delatores, victimarios y cómplices de un estado de terror que persigue a los "sediciosos", allana sus casas y ofrece recompensas a los ancianos que contribuyan con actividades de denuncia. Un mundo que rechaza a los niños se articula y combina semánticamente con la negación de traer hijos al mundo para no "contribuir al fisco". ${ }^{2}$ Al mismo tiempo si una madre (relato 6) puede negarse a pujar para no ayudar al nacimiento de su hijo, en otro de los relatos un hijo puede desear encerrarse en la cripta de la madre para alcanzar la unión con ella ("De todos mis suicidios,

\footnotetext{
${ }^{2}$ Ver los poemas 21 y 22 que reiteran a través de enumeraciones negativas la decisión de no tener hijos ni dejar brotar semillas.
} 
solamente uno no había probado: encerrarme en la cripta con mamá. Estaba seguro de no fallar”, 163). ${ }^{3}$

Las ficciones que Cristina Peri-Rossi inventa en 1969 podrían formar parte de un manual de biopolítica foucaultiana. ${ }^{4}$ En él se podrían ir siguiendo los avatares del pánico, los devenires del terror, sus modalidades insignificantes pero espectacularmente siniestras, los cuerpos-especies que como soportes de los procesos biológicos muestran al biopoder como, en palabras de Foucault, "un elemento indispensable del capitalismo" que se afirma "al precio de una inserción controlada de los cuerpos en el aparato de producción y mediante un ajuste de los procesos de población a los procesos económicos” (170) En la frase final del poema 20: "No araré más,/no cultivaré retoños/ ni hijos/ no volveré a subir/ No cuajaré más en tu vientre/... Todo por no contribuir al fisco”, se advierte ese ajuste biopolítico que se traba entre dictadura y capitalismo.

LA TOMA DE LA PALABRA

Peri-Rossi dibujó terrores, pronosticó catástrofes, respiró anticipadamente el hedor de los cadáveres, escuchó los sonidos de las sirenas y los gritos de los torturados, prefiguró a los presos políticos e incluso a los desaparecidos. ${ }^{5}$ En síntesis, imaginó la destrucción. ${ }^{6}$

\footnotetext{
${ }^{3}$ Entre las posibilidades de la sexualidad, representadas en general bajo formas ambiguas pero no amenazantes, las relaciones incestuosas entre hermanos o entre madre e hijo son las únicas que aparecen en tramas felices que respiran placer y entendimiento. En el impecable y maravilloso relato "Despedida de mamá" se cuenta la historia de incesto entre D.H. Lawrence y su madre; el relato de la gestación y el nacimiento que ella le repite al hijo resulta una de las delicias de la convivencia, además de los acoplamientos versátiles y maravillosos que mantienen. "El único dolor que experimentara Lawrence era no poder ser parido nuevamente. No está muy seguro de que el hijo que resultara de sí y de su madre, fuera otra vez él mismo, por lo cual desistió del proyecto” (127) Como un Edipo no arrepentido ni maldito Lawrence prefiere la omnipotencia de ser hijo y marido de su madre pero se detiene ante el temor que le produce la idea de fealdad que pueda portar un vástago que no se le parezca.

${ }^{4}$ Michel Foucault avanza en el análisis del derecho de vida y de muerte del poder soberano y su transformación hacia el siglo XVIII en una biopolítica que se constituye alrededor de las disciplinas del cuerpo y las regulaciones de la población. Dice: "Si el genocidio es por cierto el sueño de los poderes modernos, ello no se debe a un retorno, hoy, del viejo derecho de matar; se debe a que el poder reside y ejerce en el nivel de la vida, de la especie, de la raza y de los fenómenos masivos de población”, Foucault (77).

${ }^{5}$ En el relato 26, “Los trapecistas”, se lee: “en lugar de la cruz los clavos y el martirio,/la cárcel, la tortura y la muerte/La ergástula el gueto el flagelo/la selva el alambrado la picana/una muerte inominada, “desaparecido”, “ignórase su paradero”, “accidental”, “casual”, “descuido” “involuntario” (67).

${ }^{6}$ El poema 42 ilustra de manera perfecta esta situación: "He venido en tren/ he gozado de los panoramas/ al pie de tu ciudad/ te digo:/ hay un aire de cataclismo/ atmósfera de desastre/plenilunio de catástrofe/ Hay/ por tu ciudad/un vigésimo niño que mendiga/y óleos de musgo cuelgan/ de los viejos edificios/ hay/ una incertidumbre/vástaga tragedia/ hay/un olor a rencor y muertos/ que me asfixia/ o será este silencio de diez de la noche por la calle/ la ciudad sin autos/ la ciudad con miedo/ y mil y un refugiados que se esconden en los bosques/ de tus perímetros balnearios/ y quince mil presos políticos/gimen en pesebres/ Hay/ una lucha subterránea/ un miedo opaco/ un césped seco/
} 
A pesar de que percibió en las fantasías maternas un espacio de miedo y alucinación fértil para la indagación ficcional no pudo anticipar las torturas sobre los cuerpos de las embarazadas, las condiciones de vida en los campos de concentración o la expropiación de bebés.

"El secuestro de recién nacidos indica el estado de esclavitud al que fueron sometidas por el Estado las mujeres que los dieron a luz. La recuperación del nieto habla del intento de redención de la madre-hija por la madre-abuela” (275), señala Martha Rosenberg. ${ }^{7}$ En estas escenas siniestras se juega la posibilidad de reescritura de una filiación y la capacidad de volver a contar una historia que, en la mayor parte de los casos, no pudo ser contada por sus verdaderos protagonistas. Los testimonios de las guerrilleras madres, las que se embarazaban durante las épocas de militancia y clandestinidad, las sobrevivientes, las que sufrieron cárcel y recibían las visitas de sus hijos pequeños, son relatos recuperados en estos últimos años que narran el horror de la maternidad en esos contextos. ${ }^{8}$ En cada historia de expropiación y reapropiación de niños se registra la historia de una madre y uno o más niños en el abismo absoluto de la separación violentada. Como una respuesta casi inmediata a las desapariciones y muertes de familiares, la emergencia de grupos autogestionados de mujeres como Madres y Abuelas de Plaza de Mayo promovió nuevas formas de hacer política cuyo soporte estaba dado por la puesta en escena de una representación social de base materna e inédita hasta ese momento. Entre unas (hijas desaparecidas con maternidades truncas) y otras (madres y abuelas en pie de lucha) se tendieron lazos generacionales que, signados por la violencia, la interrupción y la destrucción estatales pero también por la demanda de justicia, el reconocimiento de la filiación y la identidad, dieron lugar a la reformulación de los imaginarios maternos. ${ }^{9}$

una sensación de resentimiento/y un silencio agorero/ negro pájaro de muerte/ que anuncia por todos lados/ la venida de otros tiempos.”

${ }^{7}$ Rosenberg analiza el punto de intersección entre trabajo político y trabajo subjetivo del duelo que se da en las prácticas y los discursos de Madres y Abuelas de Plaza de Mayo. Especialmente, en el caso de estas últimas profundiza en las cargas subjetivas y políticas que interfieren en la recuperación de nietos apropiados. Resalto la seriedad de este ensayo que incorpora además una perspectiva feminista para tratar un tema altamente complejo.

${ }^{8}$ Moreno reflexiona acerca de cómo la maternidad fue motivo de debate en las organizaciones armadas. Para ello toma el testimonio de algunas mujeres guerrilleras o militantes y destaca que "Para muchas compañeras, en nombre de los riesgos que se corrían, los niños debían ser la reserva para los tiempos de paz, para otras constituían un talismán para alcanzar el futuro y los testigos de la revolución efectiva” (105). Otros relatos pueden leerse en el libro de Diana. En Gelman y La Madrid pueden seguirse algunos testimonios de hijos-as sobre sus padres. Sobre la vida en los campos de concentración véase Calveiro y Traba, novela en la que es posible leer la confrontación de dos posiciones frente a la maternidad, sostenidas por cada una de las protagonistas que pertenecen a diferentes generaciones: la de la militante que perdió un embarazo por torturas y la de la mujer más grande, próxima a las ideas y luchas de las Madres de Plaza de Mayo. En el despliegue de ideas y pensamientos de cada personaje se exhiben no sólo las propias ideas sobre el significado de traer hijos al mundo en ese contexto de dictadura sino también la valoración que del mismo hecho realiza la otra mujer. La novela transcurre en Uruguay, pero su referencialidad política abarca también a Argentina y Chile.

${ }^{9}$ Un texto de Laura Bonaparte (“La memoria y la carne”), miembro fundador del grupo original de Madres de Plaza de Mayo y que, en 1986 cuando el mismo se escindiera pasará a formar parte de 
Estas transformaciones se verifican especialmente en las instancias de apropiación y constitución de una palabra nueva. En 1977, cuando Madres y Abuelas de Plaza de Mayo sacan la maternidad del ámbito doméstico para ubicarla en la plaza están construyendo las condiciones para la elaboración de nuevas representaciones sobre la maternidad. Las salidas al espacio público para impugnar las políticas del Estado genocida les permitieron a estos grupos hacer visibles las desapariciones de sus hijos, pero también fueron la base de los primeros escarceos en la construcción de una representación que simultáneamente se entrelazaba con las posibilidades de autorrepresentación. Se produjo entonces un momento de "toma de la palabra", es decir, un espacio-tiempo de representación que se definía por su oposición a las políticas del Estado terrorista. Michel de Certeau considera que esta "toma de la palabra” se constituye como un acontecimiento, ${ }^{10}$ es decir, no sólo como un lugar de enunciación sino como una instancia que produce distintos tipos de acciones y transformaciones en la cultura instalando una nueva relación de fuerzas. Esta irrupción es percibida, en general, como una malformación y, en tanto no puede ser captada por los sistemas de conceptualización imperantes es empujada hacia una exterioridad donde sus responsables son tachados de locos o subversivos. El surgimiento de las Madres de Plaza de Mayo en la escena política en 1977 fue tachado de "locura”, locura de unas mujeres que se separaban del discurso domesticado de la maternidad para decir lo que el poder del Estado dejaba como innombrable.

Por otra parte, este acontecimiento tiene como efecto la politización de la función materna. ${ }^{11}$ La irrupción visualiza no solo una relación particular entre madres y Estado sino que al mismo tiempo demuestra que la noción de maternidad es histórica y que, por lo tanto, siempre es capaz de revelar su vinculación con los proyectos que los Estados conciben para las mujeres y sus proles. Pero lo que trae este grupo político como novedoso es la capacidad de disputarle al Estado esa función, de cambiarle su signo. El imaginario social de la maternidad se altera por éstas y otras intervenciones y de aquí en más es imposible sustraerse a sus efectos. De modo que las voces que enuncian estos discursos de renovación simbólica provienen de diferentes ámbitos y admitieron y admiten enunciados de orden diverso. Algunas adoptaron la forma de la consigna política y acompañaron las prácticas de los grupos mencionados, otras resurgen en las formas testimoniales de los relatos de las sobrevivientes. Por su parte, las diferentes prácticas artísticas resultaron y resultan un espacio privilegiado de despliegue formal y semántico de esta cuestión. En los textos literarios pueden aparecer bajo la forma de ficciones de anticipación, narrativas realistas o fantásticas, novelas históricas o textualidades de apuestas vanguardistas. Por fin, las producciones críticas y teóricas, provenientes especialmente de la práctica y la

Madres de Plaza de Mayo Línea Fundadora, recorre el significado de las huellas que marcan en su cuerpo el recuerdo de su hija.

${ }^{10}$ Michel de Certeau analiza el proceso de Mayo del '68. Para él la toma de la palabra tiene la forma de un rechazo, es una protesta, marca y define una autonomía, le da un estilo a la experiencia.

${ }^{11}$ Las sociedades y los Estados siempre consideraron a la maternidad como una función social funcional a sus proyectos políticos. En la cultura argentina se puede pensar que durante el primer gobierno peronista también se produce una politización de la función materna a través de la construcción simbólica de Eva Perón como madre de los descamisados y Jefa Espiritual de la Nación. 
teoría feminista, resultan también otras instancias de producción y reformulación de este imaginario. ${ }^{12}$

EL MERCADO Y EL PARTO

En 1989, Diamela Eltit publica El cuarto mundo, novela cuya primera parte es inaugurada por la voz fetal de un mellizo que da comienzo a la representación de un mundo tan alucinado y amenazante como el que Peri-Rossi describía a finales de los sesenta. La pareja de hermanos incestuosos vive en un estado de alteración física y psíquica que disuelve los límites entre los momentos que comparten el espacio intrauterino y la vida familiar posterior al nacimiento. Las señales del horror entrecruzan y conectan ambos mundos. En principio, porque entre los fetos los acercamientos, posturas y arreglos corporales parecen legitimados por el espacio protector y cada vez más estrecho del vientre materno, marcado éste por una lógica cerrada e indecible que la voz que construye esta novela se atreve a modular. La perspectiva masculina del feto avizora el mundo exterior en el que vive la madre, observa sus conductas, la juzga sin piedad. El mito del vientre materno protector se torna a los ojos del mellizo “una oscuridad artificiosa”, los relatos que escucha de la madre, sobre todo los referidos a los niños ciegos, resultan "premoniciones aterrantes". "Era terriblemente duro exponerse a sus narraciones desde el sistema cerrado en que yacíamos” (20), dice el que narra. Su punto de vista soberano durante esta primera parte de la novela relata al embarazo como una catástrofe, una enfermedad, una empresa biológica cuyo destino final —el nacimiento del hijo— - se vive como una muerte. El parto, el pos-parto, el desarrollo y crecimiento de los mellizos, la relación con el nombre propio, la adquisición del lenguaje, la entrada en la adolescencia se enuncian desde una perspectiva poderosa y omnisciente que se afirma a sí misma solamente en función de las fases del amor-dolor que le ofrecen madre y hermana. Atrapado en los artificios sentimentales de una o en los ataques lascivos y celosos de la otra observa la figura distante del padre demandando un modelo masculino de autoridad que lo saque de los juegos subjetivos de oferta y demanda a que lo someten madre y hermana.

La relación fraterna domina sobre las otras; sin embargo, hermano y hermana le otorgan a ella sentidos diferentes. María Chipia, el mellizo varón de nombre femenino, relata así el episodio febril y letal de los celos de su hermana:

Ya había descifrado el sentido de su origen, cuya clave le parecía, descansaba en mí y no en mis padres.

Pensó que consumarnos como uno podía traer a la memoria el impacto real del origen y el instante único e irrepetible en que el organismo decidió la gestación. Yo había sido testigo de su emergencia a la vida y, por ello, sólo en mí descansaba la respuesta. (99)

\footnotetext{
${ }^{12}$ Lauretis señala que la construcción del género se realiza en las distintas instituciones y discursos sociales, en las prácticas artísticas, en las teorías o cuerpos de saber, en las formulaciones académicas y en las acciones y propuestas de los nuevos movimientos sociales y tanto en sus formaciones hegemónicas como en las manifestaciones no canonizadas o alternativas. La construcción del género incluye quizás como uno de sus programas centrales la renovación de los significados de la maternidad, de modo que es posible trasladar de uno a otra el proceso que describe Lauretis.
} 
A pesar de que el personaje reviste un conjunto de notas de ambigüedad, simulación y artificiosidad que lo vuelven vulnerable e inseguro, María Chipia retiene una explicación masculina y autoritaria sobre el origen de la vida y utiliza un tono admonitorio y denunciante de los actos sexuales. La madre con su adulterio “desplomó el universo, confundió el curso de las aguas, desenterró ruinas milenarias y atrajo cantos de guerra y podredumbre” (100). La transgresión materna se constituye en vergüenza familiar y la familia completa lo paga con el encierro. Este aporta el peligro mayor que siempre se cierne sobre la familia conyugal, moderna y occidental: "En ese tiempo atroz e inaugural la familia se permitió todos los excesos...” (105). Antes de nombrar y narrar el incesto y aún más, al nacimiento de un hijo como producto de él, la voz del mellizo llama al silencio, delega el poder de la confesión en su hermana cuando el pánico ya avizoró la relación entre delito, hambre y sexo: "La vergüenza de mi madre se había instalado en su piel cetrina y supurante. Nuestros rasgos, alarmados, empezaron a gesticular la condición única del pánico. Sintiéndome incrustado en un tiempo crítico, acepté depositar la confesión en mi hermana melliza” (106).

El cambio de narrador en la novela viene de la mano de la escritura. La segunda parte, a cargo de la melliza, se nombra como texto escrito y está encabezada por un título que remite oblicuamente al acto obsesivo de escribir: "Tengo la mano terriblemente agarrotada”. Pasión y fervor corporal aluden al movimiento de una escritura rabiosa y frenética y a la mano que la produce, parte del cuerpo cuya reiteración trataré más adelante.

Encierros y excesos resultan el contexto de posibilidad del relato del incesto fraterno que se narra en la positividad de su goce y no a través del tono vergonzoso de la voz masculina de la primera parte. De modo que la transgresión forma parte de un deseo de afirmación, de un acto de resistencia. La narradora lo grita "Quiero hacer una obra sudaca terrible y molesta”. El tipo de fecundidad que la narradora busca y que logra solo puede forjarse con esos atributos. La "obra" se realiza frente a los ojos de los padres y la segunda hermana, invirtiendo también el escenario de actuación y a los protagonistas de la escena primaria. El goce repetido, el desenfreno sexual, el vicio, la cercanía con el crimen y el delito se narran una y otra vez rodeando al estigma que los hermanos actúan y representan mientras simultáneamente convierten a esa "mácula” en un signo de resistencia. El único modo de construir este espacio dentro de la familia conyugal, estereotipada en sus marcas violentas (un poderoso y autoritario desdén paterno es atacado socialmente por la evidencia del adulterio materno) y asociada en función de estos rasgos con la "nación más poderosa del mundo" es a través de la fraternidad, “sólo la fraternidad podía poner en crisis a esa nación” (124). La melliza no solo levanta la bandera de una fraternidad revulsiva y resistente sino que para contribuir a la demolición de las perversas asociaciones entre nación y familia cree que hay que volver a contar este relato en clave genital: "No te perdono, pues aún temes a mi anciano padre, que no ha derrotado a su virilidad. [...] Temes a mi hermana y a mi madre, y parece que la multiplicidad de tus sueños te acercara a la nación más famosa y poderosa del mundo. Pero yo, que leo y traduzco cada movimiento en la genitalidad de la familia...” (130). Fervor y propuesta femenina que hacen que el deseo de fecundidad se cuente tanto en términos de genitalidad como literarios. La niña que en el cierre del texto nace para ser vendida se descubre como “obra”, fruto de un deseo 
“terrible y molesto” de una narradora de nombre disminuido, “diamela eltit”, que allí, en el cierre es descubierta en tanto madre y narradora con nombre propio. ${ }^{13}$ Gesto de escritura que Eltit reiterará en Los vigilantes (1993), como si en los finales, en los cierres de aquello que se fue mostrando en su proceso de construcción y que ahora se revela como producto, artefacto, obra, pueda reconocerse una posesión, una maternidad, una firma y un origen. El incesto, entonces, en lugar de acoplarse al estigma, adopta el legado de una fraternidad nueva y poderosa, manifiesta el entramado capitalista establecido entre Estado, familia y sexualidad, señala a la biopolítica como base de ese tejido y exhibe a la literatura como el espacio donde los hijos del incesto se nombran como "manifiesto”. Declaración de origen que no niega a la madre, declaración de guerra que sitúa y enfoca a los enemigos, declaración de principios que hace del hecho estético un acto al mismo tiempo político.

En el límite, llegué, siempre a horcajadas, a perder la noción del tiempo, pues se disolvió la frontera entre exterior e interior y María Chipia se integró a mis estructuras neuronales. Perfectos, únicos, estuvimos desde el amanecer hasta la noche avanzada, encontrándonos hasta fundirnos. El niño sufría. Su sufrimiento, también, fue integrado por nosotros ya sin culpas, sin angustia, ausentes de todo mal.

Fue un homenaje a la especie sudaca. Fue un manifiesto (152)

El hijo-obra producto de este encuentro, decididamente situado fuera de la ley, si va a la venta irá en tanto desecho, resto, desperdicio, participará del mercado pero tampoco contribuirá al fisco, como la criatura imaginada pero no querida de uno de los poemas de Peri-Rossi.

La mayor parte de los textos de Diamela Eltit dan cuenta de la alianza delictiva que se arma entre poder político, poder patriarcal y poder económico. Se trata de una asociación que actúa para la escritora “inoculando miedo", depredando al Estado, "trabajando contra la memoria”. Eltit se ha referido también a lo que ha significado para ella escribir bajo dictadura, "algo pasional y personal. Mi resistencia política secreta”. ${ }^{14}$

LA SANGRE, LA MADRE Y EL DEDO

Cada novela de Eltit se constituye en el espacio verbal donde alguna mujer expone su cuerpo y su discurso, oral o escrito, en el centro de las luchas y violencias familiares, sociales y urbanas. Algunas de ellas construyen una figura que concentra en su mano la marca violenta de un capitalismo criminal. La madre que gobierna el espacio narrativo de Los vigilantes y siente "encima el malestar que me ocasiona el cuerpo agarrotado por la mala postura” o reconoce que "mi mano escribe hoy aterida...” conforma una escritura que

\footnotetext{
${ }^{13}$ Consultar Morales, donde la escritora se refiere a que con la inclusión al final de su nombre propio pretendía no dejar afuera el proceso de escritura, dar cuenta de esa experiencia en otro registro. Con el uso de la minúscula buscaba desafiar la institución "autor” y “novela” y dar cuenta de esa novela "sudaca" que iría a la venta como parte de todo lo que se estaba vendiendo en ese momento en Chile, gracias a una depredación fuerte e impune del Estado. Por otra parte, Eltit se ha referido en muchos de sus trabajos críticos a las relaciones entre mercado y literatura. Véase Emergencias.

14 "Errante errática" en Emergencias.
} 
en su obstinación acompaña las heridas de un cuerpo femenino o su revés, un cuerpo femenino que nombra sus lesiones a través de los puntos de tensión de una escritura violenta. Por su parte, Los trabajadores de la muerte (1998) comienza con un recorrido espacial por un albergue y una taberna y distingue en ese marco la presencia de una niña con el brazo mutilado que, escoltada por dos inválidos, pide un vaso de vino que toma con su única mano. Figura de margen absoluto, esta niña, que si bien "carece del instrumento corporal para la escritura, insiste en la oralidad para controlar el espacio cultural de la narración” (172), ${ }^{15}$ resulta por ausencia la contrapartida de aquéllas que tozudamente escriben mientras sus dedos inevitablemente se encallecen. Estas mujeres, expuestas a diferentes variantes de la intemperie, construyen sus propios destinos de desamparo, caminan hacia los límites de una casa, de una ciudad, de una lengua, de una familia. Aquí el incesto, la traición o el matricidio se cuentan como versiones "localizadas", "sudacas" de relatos inmemoriales.

Otra versión de la relación madre-hija próxima en cuanto a sus figuraciones y sentidos a las anteriores se puede leer en los dos personajes del relato "Consagradas" (incluido en la antología Salidas de madre), donde una madre y una hija ancianas (la hija de sesenta, la madre de ochenta) disputan en un contexto urbano de hordas "regidas por pasiones políticas”, acuerdos económicos usureros, respiraciones asmáticas y cuerpos brotados por alergias, quién se queda con el poder de la escritura. Una violencia de base recorre el texto desde el comienzo al final; la hija expresa que su mano derecha es la más valiosa de sus pertenencias y el texto se dedica a contar el proceso a través del cual la madre le arranca uno a uno los cinco dedos y se los va devorando. La hija narradora no abandona su lugar de enunciación pero lo hace al precio de una humillación y maltrato progresivos. A partir de la primera mutilación, exhibirá su derrota al mismo tiempo que la transformará en desafío y bravata (“Cuatro dedos y un orificio”, "Mi orificio vale oro. Del más alto kilate”, “Jamás dejaré que nadie examine mi orificio, ni pretenda curarme el orificio. Es mío. Mío y de los dientes sagrados de mi madre”). El acto a cumplir es un acto límite, final, absoluto, ¿Cómo escribir sin la mano?, ¿qué escribir cuando esa mano es mutilada por una madre, que, de esta manera, procura impedirle el camino a la escritura? Sólo se puede contar el relato de esa pasión, de esa mutilación, narrando y ubicándose en esa zanja, en esa hendidura de sangre que produce el orificio, haciendo del orificio un baluarte y mimetizándose con él. Un yo que resiste con dos dedos, un yo-muñón, un yo-orificio, un yo al que si le obstaculizan su camino a la escritura se impone de todos modos escribir el agujero:

\footnotetext{
Agarrar un carbón con dos dedos, escribir sí sí silábica con mis únicos dos dedos. No se sabe cuándo se desencadenará el definitivo ataque de asma. No se sabe, tampoco en qué momento las nuevas tendencias políticas rendirán una cuenta pública sobre el botín producto del pacto. Lo que sí sabemos es el riesgo creciente que minuto a minuto experimenta mi orificio. Sabemos, ya sabemos todo en cuánto se arriesgan las perforaciones, los abismos, las zanjas, los boquetes, los resquicios, cómo cualquier abertura convoca las
}

15 Masiello lee en detalle la función narrativa de esta figura y su participación e inmersión en los espacios marginales y populares como una marca de la narrativa de Eltit. También es interesante en este artículo la lectura sobre el uso y función de los mitos en su narrativa. 
peores intenciones, los más abyectos impulsos. Mi orificio, tan expuesto ahora, podría convertirse en el lanzadero de las miserias que acumula mi madre.

¿Dos deditos? Uno y uno.

Ni un solo dedo y el muñón. Con el último mordisco, se fueron mis últimos dos dedos. Pensé prevenir, dilatar; pensé que había aprendido a adelantarme a cada uno de sus pensamientos.

Soy un orifico a punto de despeñarse. Me muevo torpemente con mi muñón envuelto en trapo. Toda yo orificio... (103)

Toda pareja -filial, fraternal, conyugal — que habita los textos de Eltit contiene una “masa impresionante de pasión” y si se empapa de sangre, hurga en la basura, frecuenta tabernas, escapa de las leyes de la ciudad, se sumerge en el incesto y en historias de delitos y crímenes es porque en estas relaciones que se traban se juega algo más que los vínculos familiares. Ese algo más es el punto en el que familia, sexualidad, narrativa y Estado colisionan poniendo en el centro la vida y la muerte, la constitución de la maternidad y la posibilidad de los nacimientos.

EL VIAJE Y LAS CENIZAS

En El Dock de Matilde Sánchez, estas relaciones que venimos delineando adoptan otros anclajes. El texto se construye sobre el espacio vacío que deja una maternidad biológica y en esa ausencia se teje un universo de interpretaciones cuyos protagonistas son un niño y una mujer soltera, sin hijos, amiga de la madre muerta. ${ }^{16}$ Colocados en una situación que ninguno de los dos podía haber previsto o pronosticado, la nueva pareja filial hace de esos sitios lugares de construcción de nuevas subjetividades: la de hijo y la de madre. Sujetos y lugares se revelan como contingentes y abiertos al descubrimiento del otro. El desplazamiento de lo biológico hacia el encuentro subjetivo y cultural hace que en la figura del hijo no se deposite un lugar de trascendencia materna dada por la continuidad ni de reproducción de la especie. Madre e hijo deben atravesar historias, nombres propios, recuerdos, rostros, cuerpos y relatos para mostrar a esta relación como un lugar de aprendizaje, de construcción y de escritura.

En los actos de dar vida (al hijo) y de dar la vida por una causa que lleva adelante la madre biológica, la falsa Poli, la amiga, la guerrillera, se concentra el debate sobre el significado de la maternidad, sus riesgos y sus límites. Poli será el objeto de interpretación; los que arman su experiencia y construyen su subjetividad sobre el terreno que su muerte deja vacante, los interpretantes. Las dos mujeres, la guerrillera y su amiga, la narradora, pertenecen a la misma generación que los y las jóvenes apresados y desaparecidos durante la dictadura, son sobrevivientes de ese estado de violencia e indefensión y revelan las trazas diferenciadas que ese gobierno dejó en los ciudadanos. Por otra parte, el niño, hijo

\footnotetext{
${ }^{16}$ El ataque guerrillero al Regimiento de la Tablada, ocurrido en 1989, es retomado y transfigurado en esta novela. La narradora descubre que la mujer joven que ve morir en la pantalla del televisor es su amiga de la infancia a la que no ve desde hace un tiempo. Poli, la militante, había preparado todo para que, frente a la posibilidad del fracaso del ataque, su amiga se hiciera cargo de su hijo. Para un análisis más exhaustivo de esta novela consultar Domíguez; Adriana Amante y David Oubiña.
} 
de la primera, contiene en su figuración textual las marcas del abandono, de la orfandad y, por lo tanto, de la posibilidad de construir a partir de estos datos algún relato de reinserción en la familia biológica o de adopción. El Dock elige esta última perspectiva y pone el acento en el carácter doble de la adopción. El Dock es también una novela de sobrevivientes y sobre la sobrevivencia.

La narradora, que se convierte en madre durante el transcurso de la novela, va reflexionando y midiendo paso por paso sus acciones y sentimientos, registrando las marcas de éstos sobre su cuerpo y el cuerpo del niño e inventando una serie de ficciones y relatos que funcionen como el germen de una memoria compartida entre ambos. La novela se propone como un relato de descubrimiento del otro y, al mismo tiempo, como el recorrido por un proceso de subjetivación materna. Pero, sobre todo, se pregunta cómo narrar ese encuentro, cuál es el tipo de textualidad y el orden temporal que puede abarcarlos. Cuando comienza la novela la futura madre y el niño se miden como extraños, ella en tanto narradora funda su autoridad textual y constituye a Leo como un texto. Si Leo es el objeto permanente de interpretación todo a su alrededor es móvil, derivado, abierto, cambiante, sujeto a la confrontación especialmente establecida cuando él reniega de su lugar de objeto y disputa la interpretación sobre la vida de su madre y los relatos que le cuenta la narradora. El proceso de reconocimiento no implica únicamente un recorrido de lectura sino de escritura; la narradora escribe a Leo, captura al hijo en el texto. Este no lo reemplaza, sino que se constituye como el efecto y el acto de escribir y colocar al hijo y a la madre en el centro de la representación como entidades a explorar en sus múltiples devenires y subjetivaciones.

Novela de nacimiento plural, compartido y moroso como el relato que lo transporta y que al hacerlo vuelve sobre ese hecho una y otra vez, rodeándolo, singularizándolo, interrogándolo en sus potencialidades para la acción y la práctica subjetivas pero también en sus inscripciones políticas y, a un mismo tiempo, literarias. Novela de nacimiento demorado que requiere previamente del relato de la muerte y de la vida de Poli para poder comprender sus dilemas, que precisa del relato del viaje más allá de las fronteras del país, que reclama los rituales del duelo (la narradora y Leo comparten la única ceremonia en honor de Poli; esparcen juntos sus cenizas en el Arboretum de Solís) para poder alcanzar finalmente el relato del reconocimiento y la adopción.

Esta novela de Matilde Sánchez puede, entonces, también ser leída como un tratado sobre la adopción y, en este sentido, reenvía a una de las consecuencias más nefastas de la represión durante la última dictadura: el secuestro y apropiación ilegítimas de los hijos de desaparecidos. El Dock elige otra vez una representación oblicua de esta situación histórica. La decisión de ofrecer el niño en “adopción” pone en contacto un sujeto de identidad precisa y reconocible, la amiga-la madre, que realiza una delegación conciente de su hijo a la narradora. El encuentro o pacto simbólicos que se entablan no son ilegítimos, tienen la legitimidad de la historia personal entre las dos Poli. En este sentido, no afecta el conocimiento generacional como elemento en general constitutivo y frecuente de toda adopción o como marca siniestra de borradura en el caso de apropiación de hijos de desaparecidos. ${ }^{17}$ Más bien lo desvía privilegiando una genealogía no basada en lazos de

\footnotetext{
${ }^{17}$ Véase Giberti y Chavanneau de Gore.
} 
sangre sino de amistad. Por otra parte, la verdadera historia familiar del niño se conserva por medio del viaje a Solís, a la vieja casa de veraneo de los Behn, herencia familiar de Poli. Pero, sin embargo, desde la perspectiva de las leyes del Estado la convivencia con el chico es considerada ilegal. Ellos actúan esa clandestinidad al salir del país burlando las vallas aduaneras. La narradora, como sobreviviente de una época y una generación, tiene la experiencia necesaria y sabe que poner al niño ante la ley significaría ponerlo en peligro. Salir de los límites de la nación implica enfrentar un nuevo peligro y al mismo tiempo colocarse más allá de la ley; también implica cumplir con los deseos del niño que había programado con su madre las vacaciones en Solís. El viaje y el conjunto de pasajes subjetivos que enfrentan son necesarios para la construcción de la relación materno-filial y para el desarrollo narrativo. Una vez que se producen estos pasajes madre y niño están listos para volver al país y "arremeter de una vez con el infierno de papeles que nos esperaba” (291). Volver al país, volver a la ley, significa aceptar los términos de una justicia, significa aceptar que hay un tercero al que apelar, situación ésta que no se daba durante el terrorismo de Estado. Los personajes de la novela solo pueden hacerlo una vez que han atravesado un proceso subjetivo y narrativo de aceptación y reconocimiento mutuos. ${ }^{18}$ El escorzo textual, a pesar de su corrimiento temporal, sitúa los términos de un debate social y político que incumbe, además, a la elaboración de la memoria histórica. En esta novela no hay ocultamiento o desinformación que desandar como en el caso de los niños apropiados y restituidos sino una proliferación de relatos que se van construyendo de a dos. Aquí El Dock produce su desvío, en tanto lectura crítica de lo históricamente dado, y a través de él su ética.

\section{LÍMITES Y DESMADRES}

Estos relatos maternos exhiben sus escapadas de los perímetros de la ley, sus transgresiones desidentificatorias de las narraciones hegemónicas y de sus encorsetadas sintaxis. Las salidas se juegan en términos violentos no sólo porque en su variedad narrativa los textos tratados eligen, para situar sus representaciones, épocas próximas y similares en cuanto a sus marcas violentas (los años previos a la dictadura en Uruguay en Peri-Rossi, las inmersiones en situaciones de terror estatal en las novelas referidas de Eltit, los primeros años de la posdictadura en Sánchez) sino porque estas narraciones, enunciadas desde voces femeninas en posición de madres, cuentan a la maternidad como una experiencia límite.

El tratamiento de los límites, el cuestionamiento a las leyes, que circunscriben el circuito del fuera de lugar y del salirse de madre, no se reduce a contar antagonismos de corte político. El trabajo con las figuraciones marginales de la maternidad, es decir, el detenimiento en lo que ella tiene de experiencia límite se dirige directamente a la impugnación de las leyes familiares. Estas incluyen el sistema de alianzas, la prohibición del incesto, la ley de heterosexualidad obligatoria. El movimiento original y marcadamente político que realizan los textos analizados se basa en que combinan un ataque hacia ambas

\footnotetext{
${ }^{18}$ Véase Ulloa.
} 
esferas, la política y la familiar, para desmontar a través de las ficciones que las rodean los engranajes perversos que sostienen los vínculos entre familia y Estado, entre sexualidad y política. Entre estas relaciones, sosteniéndolas y atravesándolas, se instala otra pregunta. Ella se interroga por el tipo de textualidad y la forma literaria posible que permitirán ajustar y desajustar las relaciones.

Póstuma es la primera novela de la chilena Lina Meruane cuya estructura entrelaza dos espacios narrativos independientes pero alternados y relacionados. Uno de los textos está escrito en primera persona. La narradora, Renata, cuenta la historia de amor con su abuela Amanda, un relato de aprendizaje donde el capital simbólico que se transmite está vinculado con el erotismo y la escritura. Los escarceos eróticos se aprenden en el cuerpo de la abuela y en el abandono de su propio cuerpo a las caricias de ella. La novela disuelve todas las certezas narrativas; la confusión abarca diferentes niveles textuales al punto que dudamos de la consistencia de voces y personajes. El doble relato se obstina porfiado en la representación de mundos exclusivamente femeninos, disponiendo en ellos un número amplio de placeres y crueldades. Las escenas eróticas entre mujeres se dan dentro de los límites familiares desplazándose entre cruces incestuosos; el deseo fluye además perversa y asfixiante entre generaciones de niñas y abuelas ("Mi abuela prematura, recién parida, a la que iba secando ahora con mis labios (...) y puse la lengua sobre su pecho, y mamé de ese pellejo manchado hasta que el pezón empezó a crecer en mi boca.”, 195). El otro cuerpo textual, escrito en tercera, va siguiendo la convivencia entre Renata y una niña de cuatro dedos, remedo de los personajes de Diamela Eltit. La representación de la niñez no retiene ninguno de los tintes de ingenuidad, pureza o perfección. Los contactos corporales se renuevan tanto como los ensayos con la droga. Cada uno de los conjuntos experimenta sobre los límites (de los géneros, de las relaciones familiares, de las tramas narrativas, de las voces) y es allí donde al romper con todos los moldes recibidos, pacta con la muerte. Asesinar a la abuela moribunda y morir con ella es el acto de amor que cierra la novela; en él se consuma también la destrucción textual. Lo que sobrevive se nombra como “nuestro cuerpo", una metonimia póstuma que hace del cuerpo textual una masa incestuosa que se cuenta como un legado entre mujeres.

“Amaría la maternidad si pudiera ser Yocasta” escribe Ana Miller, la pintora vanguardista nacida en los años veinte cuyos diarios íntimos se siguen en la novela Ana M. 1945 de María Gabriela Ini. Yocasta condensa el deseo de un modelo materno, una suerte de original que excita por la audacia y el poder de transgresión de tener hijos con el propio hijo. Modelo, además, de fecundidad, fatalidad y catástrofe. El personaje de Ana ama de Yocasta su falta de límites, se obsesiona con engendrar y concebir o sueña que da a luz niños muertos y procrea monstruos, puede desear que si no hay hombre al menos haya hijo o que tendrá un hijo cuando no haya hombre. A lo largo de la novela mantiene una relación cambiante con su propia maternidad: del aborto al arrepentimiento por haberse negado a dar vida; del deseo de hijo con diferentes hombres a la idea de "maternidades culpables” y "partos criminales” como los de Yocasta o a las "maternidades inútiles” de las monjas. A través de la representación de embarazadas que paren en cautiverio (personajes que pinta en sus cuadros y que remiten al horror nazi) Ini está instalando de manera oblicua en la ficción uno de los relatos neurálgicos del horror de la dictadura de 
1976. ${ }^{19}$ Por otra parte, Ana Miller es hija de un rechazo materno que de algún modo signa la relación de ella con su hija Josefina. Ni madres ni hijas responden a los modelos cristalizados del amor incondicional sino que por el contrario resultan representaciones audaces y extremas de una relación conflictiva, contradictoria y paradójica. La última entrada al diario, el día previo a su suicidio, Ana Miller escribe un poema para su madre, un poema incestuoso, de orgasmos y "útero sangrante”, un poema de regreso al vientre materno para encontrar su "última morada”.

Por último, en Divina anarquía de Belén Gache no hay incesto por descubrir ni pasión por experimentar. El personaje y narradora, Antígona, es un puro nombre cargado de significados cultos y trágicos pero entregado a distintas formas del despojo y de la pérdida. La novela, conformada por cuarenta capítulos breves, va contando la historia de esta joven que, al comenzar el texto, está enterrando a su hermano, el último personaje que queda de su familia. Se trata de una pareja de huérfanos, recogidos en la calle durante la década de los setenta por Felicitas, la madre adoptiva que los cría. El final de la novela muestra a una joven de mochila al hombro que perdió todo (familia, casa, amigos, trabajo) y que se va portando la mueca de una nueva indigencia. El texto se hace cargo del viraje de la violencia que se dio en el contexto argentino. Es decir, del pasaje de la violencia del Estado terrorista en la década de los setenta y comienzos de los ochenta a la de la exclusión económica producida por la aplicación de las políticas neoliberales durante los períodos democráticos siguientes. A pesar de que en Divina anarquía se puede leer la representación velada de una historia de niños-hijos de desaparecidos ${ }^{20}$ lo que cobra fuerza en el texto es esta nueva imagen de la exclusión y la aparición literaria de otro tipo de sobreviviente. A partir de este momento, Antígona, personaje de consistencia referencial fuerte, podría aproximarse al alucinado niño imaginado por Peri-Rossi que sobrevive en el frasco o a las niñas mutiladas de Eltit o Meruane en tanto ninguno de ellos podrían formar parte de un registro de ciudadanos. A Leo, en cambio, le queda la posibilidad de la reflexión o, quizás de la militancia. ${ }^{21}$

Diamela Eltit se ha referido a las relaciones históricas que se entablan "entre cuerpo, poder e indefensión” (Emergencias 23). Estas asociaciones se encaran en El Dock como una acción contestaria contra las prácticas vergonzantes del Estado posdictatorial. La novela de Sánchez se detiene en la narración de cada acto, de cada gesto, de cada práctica

\footnotetext{
19 “En los campos había mujeres. Sueño que soy una mujer del campo. Embarazada, con mi panza enorme, camino cerca del alambre, pensando que mi hijo nacerá en este cautiverio atroz. Mi hijo es judío, como aquellos niños de los campos. Su sangre, su historia, su memoria son judías. Podrá llorar y reír como no pudieron hacerlo los hijos de las madres de los campos. Cómo pudieron meterlas embarazadas en los trenes, con otros niños quizás, entre los brazos; llevarlas a la muerte con la vida en el vientre. Cómo pudieron ayudarlas a dar a luz, sabiendo que matarían luego a los bebés recién nacidos y más tarde a ellas mismas, con los pechos llenos de leche y las entrañas destrozadas” (323). ${ }^{20}$ Tema que lamentablemente no puedo desarrollar en esta oportunidad por falta de espacio y que se articula también con la apuesta de la novela a las codificaciones "trágicas" como un modo de simbolizar el presente.

${ }^{21}$ Amado ve en las preguntas que se plantea Leo acerca del más allá y del universo cósmico un tipo de interrogación que no desentonaría con las que se hacen los participantes en la agrupación HIJOS "ni en su carga implícita de reproche y admiración, ni en el desarreglo temporal que conlleva”.
} 
que las instituciones estatales planificadamente dejaron de hacer con los cuerpos de los desaparecidos. El texto presenta, exhibe un cadáver, cuenta su vida, se hace cargo de su entierro, de sus pertenencias y descendencia, trata de rearmar la biografía quebrada de este hijo, relata el modo que adopta la recontrucción de su identidad. La novela muestra y hace lo que el Estado no hizo. Un realismo reflexivo y sin estridencias acompaña su tarea.

Por su parte, Diamela Eltit le devuelve al Estado sus despojos, le enrostra sus miserias. A la impunidad del Estado, a sus implantaciones de terror le contesta con descendencias peligrosas. Su venganza consiste en hacer de los niños-mercancía un arma de rebeldía y sedición. Las novelas de Ini y Meruane despliegan a partir de primeras personas desafiantes el universo abierto y provocador de las pasiones femeninas. Por fin, en el texto de Belén Gache el relato de una joven huérfana que se retira, excluida de toda posible articulación social, constituye la imagen perfecta de un Estado en retirada.

\section{Bibliografía}

Allende, Isabel y otras. Salidas de madre. Prólogo de Alejandra Rojas. Santiago: Plantea, 1996.

Amado, Ana. “Generaciones, parentescos y obediencias promiscuas”. Ponencia presentada en las Jornadas “Límites, derivas y deslindes del género”. Instituto Interdisciplinario de Estudios de Género, Universidad de Buenos Aires (Buenos Aires, 11 de octubre de 2001).

Amante, Adriana y David Oubiña. “M. Sánchez: la literatura en fuga”. Feminaria 15 (Buenos Aires, 1995).

Bonaparte, Laura. "La memoria y la carne”. La Gandhi Argentina 2/3 (Buenos Aires, noviembre, 1998): 18-9.

Calveiro, Pilar. Poder y desaparición. Los campos de concentración en Argentina. Buenos Aires: Colihue, 1998.

Certeau, Michel de. La toma de la palabra y otros escritos políticos, México: Universidad Iberoamericana, 1995.

Diana, Marta. Mujeres guerrilleras. Buenos Aires: Planeta, 1996.

Domínguez, Nora. "El desorden materno”. Feminaria 13 (Buenos Aires, 1994): 6-8.

Eltit, Diamela. Los vigilantes. Buenos Aires: Editorial Sudamericana, 1993.

El cuarto mundo. Barcelona: Editorial Seix Barral, 1996.

Los trabajadores de la muerte. Barcelona: Seix Barral, 1998

Emergencias. Escritos sobre literatura, arte y política. Buenos Aires: Planeta/ Ariel, 2000.

Foucault, Michel. “Derecho de muerte y poder sobre la vida”. Historia de la sexualidad, 1 La voluntad de saber. Madrid: Siglo Veintiuno, 1980.

Gache, Belén. Divina anarquía. Buenos Aires: Editorial Sudamericana, 1998.

Gelman, Juan y Mara La Madrid. Ni el flaco perdón de Dios. Buenos Aires: Planeta, 1997.

Giberti, Eva y Silvia Chavanneau de Gore. Adopción y silencios. Buenos Aires: Sudamericana, 1991.

Ini, María Gabriela. Ana M. 1945. Rosario: Beatriz Viterbo, 2001. 
Lauretis, Teresa de. “La tecnología del género”. Ana María Bach y Margarita Roulet, trad. Mora 2 (Buenos Aires, 1996): 6-34.

Masiello, Francine. "Los trabajadores de la muerte: estética y mercado”. Creación y resistencia. La narrativa de Diamela Eltit, 1983-1998. maría Inés Lagos, ed. Santiago: Centro de Estudios de Género y Cultura en América Latina, 2000. 167-82.

Meruane, Lina. Póstuma. Santiago de Chile: Planeta, 2000.

Morales T., Leónidas. Conversaciones con Diamela Eltit. Santiago: Cuarto Propio, 1998.

Moreno, María. "Poner la hija”. Boletín de la Biblioteca del Congreso de la Nación 120 (Buenos Aires, 2000): 97-114.

Peri-Rossi, Cristina. Indicios pánicos. 2a ed. Madrid: Bruguera, 1981.

Rich, Adrienne. "Compulsory Heterosexuality and Lesbian Existence”. The Signs Reader. Women, Gender \& Scholarship. Elizabeth Abel y Emily K. Abel, eds. Chicago/ London: The University of Chicago Press, 1983. 139-68.

Rosenberg, Martha Inés. “Aparecer con vida”. Figuras de madre. Silvia Tubert, ed. Valencia: Cátedra, 1996. 259-82.

Rubin, Gayle. “El tráfico de mujeres: notas sobre la ‘economía política’ del sexo”. Nueva antropología III/30 (México, 1986): 95-145

Sánchez, Matilde. El Dock. Buenos Aires: Planeta, 1993.

Traba, Marta. Conversación al sur. México: Siglo XXI, 1981.

Ulloa, Fernando. “La ternura como contraste y denuncia del horror represivo”. Abuelas de Plaza de Mayo. Restitución de niños: Buenos Aires: EUDEBA, 1997. 251-260.

VVAA. Salirse de madre. Idea y coordinación Hilda Rais. Buenos Aires: Croquiñol, 1989. 